\title{
The Impact of Industry 4.0 Technologies on Structural Transformation in the Manufacturing
}

\author{
Oksana Kushnirenko ${ }^{1 *}$, Natalia Gakhovich ${ }^{1}$, and Liliia Venger $^{1}$

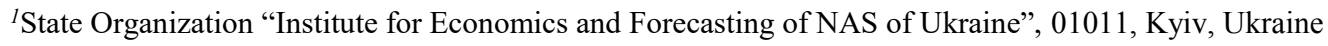

\begin{abstract}
In the paper, we investigate the impact of global trends Industry 4.0 on the structural transformations of Ukrainian industrial sector through the prism of global technological challenges. The current structural imbalances of Ukrainian industrial development and highlights the opportunities that 4.0 technologies provide for innovative industrial renewal are considered; and the readiness for adoption of innovative technologies of Industry 4.0 in the industrial enterprises is assessed. The key conclusion of the study is that further innovative transformation of global production will lead to inevitable changes in the organization and management of production processes. Based on the research results, an effective solution to certain problems has been proposed. The key finding of the research is that representatives of Ukrainian industry though perceive the importance of this tool face many obstacles in its implementation. Considering research results the efficient solutions of identified problems were proposed. They include the establishing strengthening the strategic partnership between the state science and business institutions in the process of stimulating cluster development; improvement of innovation infrastructure, creating the innovation ecosystems for the capitalization of scientific developments and the commercialization of innovations; creation of competitive conditions for all market participants, including equal conditions for access to the raw materials market, technology transfer, protection of property rights; reforming educational infrastructure; creation of a favorable investment environment with the help of mechanisms of state guarantees for foreign investments.
\end{abstract}

\section{Introduction}

At the beginning of the 21 st century, mankind was affected by the new industrial revolution, better known as the concept of "Industry 4.0 ". New technological challenges in Industry 4.0 lead to dramatic the changes taking place in consumer behavior and the management of production. Moreover, it leads to innovative transformations in many areas, breaks down barriers between them, also tended to blur the lines between suppliers, producers and consumers, and ultimately is a prerequisite for structural transformations in the economy. This has led the governments of both developed and developing countries to justify and apply new economic policy approaches to enhance the innovative development of the industrial sector. This is especially important for Ukraine, since according to Heyets V.M., the future of the country depends on the introduction of innovative development mechanisms: whether the country will move towards becoming a developed country, and potentially be left behind by emerging technologies. This is related to general patterns of social development, according to which there is a transition from a predominantly reproductive to an innovative type of development [1].

The purpose of the article is to justification of priorities for structural transformation of industrial development mindful of the increasingly important role played by the Industry's 4.0 technological challenges.
The objectives of the study are: to analyze the theoretical base for the impact of Industry 4.0 on structural transformation in industrial development; to describe the methodological approaches used in the research; to assess the industrial structure changes during 2014-2019 years; to propose policy recommendations concerning the main vector and tools of stimulating adaptation of Ukrainian manufacture to the challenges of Industry 4.0.

\subsection{Related Work}

\subsubsection{Literature Review}

There are a big number of economic publications about continuous economic, social and technological changes, which are conditioning the industrial development. In this regard, special attention should be given to the studies of Ukrainian and foreign scientists. Indeed, some experts (E. Reinert, J. Stiglitz, D. Rodrik, K. Freeman, K. Perez and others) stated that bridging the technological gap between developing countries and countries with economies in transition and others is an urgent issue, and one that impedes the global development process. In this respect, the works of Ukrainian scientists occupy a special place: V. Heyts, O. Amosha, Gritsenko, V. Lyashenko, L. Deyneko, A. Chukhno, Yu. Pilipenko, Yu. Kindzersky, L. Fedulova, in which the main guidelines for reforming the

* Corresponding author: kushnksena@gmail.com1 
domestic economy based on leading innovative industrial development. So, Yu. Pilipenko defines technology system as a relatively autonomous element of public, based on a systematic approach to the analysis of socio-economic processes [2]. As noted by Yu. Kindzerskiy, the effectiveness of structural reforms in industry can be said only when the state creates effective institutions for this [3]. Summarizing scientific research on the study of the prerequisites for technological transformations in the industry of foreign and domestic scientists, we can observe that that their driving forces are a combination of factors: the accumulation of knowledge and the search for new methods of processing raw materials at lower costs; concentration of capital; the availability of resources (human, raw materials, financial), the formation of a unified information space and an innovative institutional system. "Industry 4.0 " is considered by us as new approaches to production management and organization of production processes based on the integrated implementation of cyber-physical systems in all business processes that determine the digital transformation of the ways of human interaction, data and processes, providing new opportunities to meet the needs of consumers, using the latest bio -, nanomaterials, reducing the duration of the production cycle, reducing material costs, reducing industrial injuries, introducing circular production models, optimizing the load on the environment. At the same time, for Ukraine, which is trying to ensure sustainable economic growth and the well-being of the population in difficult conditions of a military conflict, it is extremely important to determine the features of the impact of the fourth industrial revolution on the economy and society, as well as to justify the directions of adaptation of the Ukrainian industry to the latest technological challenges.

The essence and theoretical and applied aspects of the Industry 4.0 concept as a phenomenon of the Fourth Industrial Revolution were formulated and it is proved that its emergence is closely related to civilizational development and the inevitable continuation of the change of technological orders. It has been established that the unique difference between Industry 4.0 and previous industrial revolutions are: the possibility of integrating industrial automation with control systems at the global level, transforming the concept of industrial production, activating the development of global value chains.

\subsubsection{Methodological Approach}

The research methodology derived from the basic principles for predicting the future characteristics of useful machines, procedures or working methods, which is the basis for the development of programs, ranging from forecasting the development of products or technical capabilities to creating scenarios for predicting the impact of future technologies introduced by J. Martino [4].
We have been able to build upon the R. Kurzweil's model, where he presented an analysis of the history of technology and substantiated in the Law of Rapid Return, technological changes are exponential [5] in the further discussions on this issue.

Following the European methodology, the questionnaire is the right method to identify sentiments, trends and needs of manufacturers what becomes a ground for technological upgrading. As mentioned in OECD paper "Handbook on Constructing Composite Indicators" the assessment of complex, dynamic phenomena in broad areas, such as the environment, economy, social or technological development by a system of complex indicators (Composite indicators) in different countries and recognizes them as a useful tool for policy analysis and communication with the public [6]. For example, the manual substantiates the Technological Achievement Index (TAI), which focuses on four dimensions of technological capacity.

The main method used in the study is structuralfunctional and comparative analysis - to study the factual material that characterizes the current state, the practice of structural transformation of the model of economic development.

Considering the purpose of the analytical and experimental investigation the error value is satisfactory.

The data gathered during the questioning was processed using such techniques as grouping, reduction, comparison, and graph analysis.

\subsection{Our Contribution}

These analytical materials can be implemented in programs of industry development and seek for new effective approaches of industrial development policies.

\subsection{Paper Structure}

The research is organized as follows. The first section represents the theoretical base for the impact of Industry 4.0 on structural transformation in industrial development. The description of the methodological approaches used in the research is given in the second section. The third section describes main results of the assessment of industrial structure changes during 20142019 years. At the end of the study, we conclude the survey results and give some policy recommendations concerning the main vector and tools of stimulating adaptation of Ukrainian manufacture to the challenges of Industry 4.0.

\section{Background}

\subsection{Status and characteristics of industrial development in Ukraine: trends, problems, needs}


Industrial development could be considered as the deployment of the process of "Total Causality", where factors of supply and demand interact: on the one hand, the development of industrial production creates jobs, generates income, stimulates demand, and on the other accelerates productivity growth, which in turn stimulates the growth of the welfare of the population [7]. Continuous improvement of the production base of the dairy industry, which is part of this process, can lead to increased productivity through the development of new areas of economic activity, the use of more advanced technologies, production of more complex goods and / or inclusion in international supply chains at an increasing technological level.

The key causes of economic problems during the existence of independent Ukraine and the previous period are crisis phenomena with an interval of 5-10 years, which directly influenced the development of industry. So, in the economic literature, such crisis periods are distinguished: the formation of Ukraine as an independent state (1991-1993), the signs of which were the liberalization of prices in the absence of competition and the preservation of the commandadministrative functions of the state, hyperinflation (almost 2000\%, which is comparable with the indicators of Brazil and Congo), money issue, bankruptcy and liquidation of enterprises, devaluation of deposits of the population, severing economic ties with enterprises of the former USSR; the financial crisis of 1998, caused by the unreasonable debt policy of the state, due to the state budget deficit; the structural crisis of 2003-2004, which covered the food market, financial, credit and energy systems, and the like; financial crisis of 2008, caused by debt and other obligations similar to the problems of 1998; Russia's military aggression and the annexation of Crimea in 2014 and the crisis associated with the corona virus. All of the above developmental breaks required coordinated state regulation aimed at supporting domestic industrial production in the formation and implementation of the principles of the "new industrialization" policy in Ukraine.

We determine the root causes that led to the current degradation of the economic situation in Ukraine (Fig. $1)$.

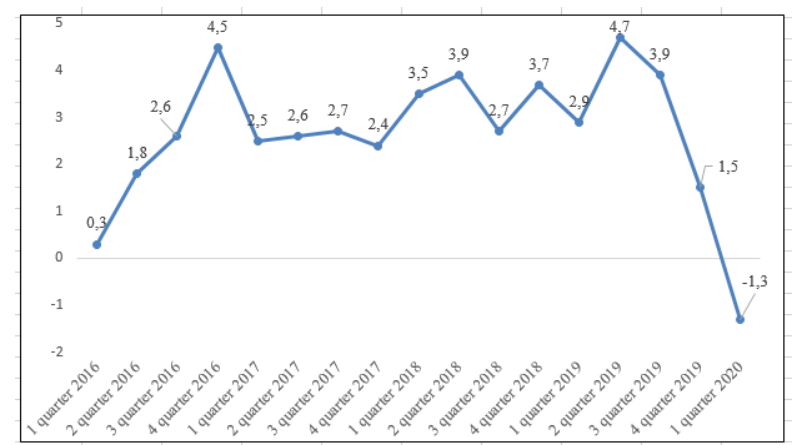

Fig. 1. Real gross domestic product (GDP): percent change from preceding quarter [8].

Once the direct causes have been identified, the next stage is to try to follow the chain of causation further.

\subsection{The basic premise of researching}

Modern practice of developed countries shows that in the Fourth industrial revolution only modern developed industry determines the rapid and high-quality growth of the economy. Increasing the competitiveness of the processing industry is of strategic importance. Thus, in Germany in 2011 the concept and industry development program "Industry 4.0 " was developed and approved. Support for the vector of Industry 4.0 forms an appropriate industrial policy, which is reflected in the implementation of various countries programs aimed at building scientific, technological and industrial potential, improving the innovation system, updating the technological base. According to European statistics, the highest concentration of hightech industries in the EU is observed in Italy, followed by Germany, France and Poland, together form more than $60 \%$ of the EU's high-tech industrial potential. For comparison, in Ukraine this sector is of very little importance. Thus, according to the World Bank, in Ukraine, the share of high-tech products over the past three years is gradually declining and in 2018 is $5.41 \%$ of industrial exports, and in 2015, this figure reached $8.52 \%$. For other neighboring countries, such as Belarus, similar trends are also observed: the share of high-tech products in exports decreases from $4.85 \%$ in 2016 to $3.49 \%$ in 2018 [10]. Instead, the world average is $16.3 \%$ in 2017. Comparing the structure of Ukraine's industry in 2010 and 2019 by type of economic activity, we can note a decrease in the share of manufacturing to $64.4 \%$ and an increase in the contribution of electricity, gas, steam and air conditioning to $18.5 \%$ and mining and quarrying up to $15.9 \%$ (Fig. 2).

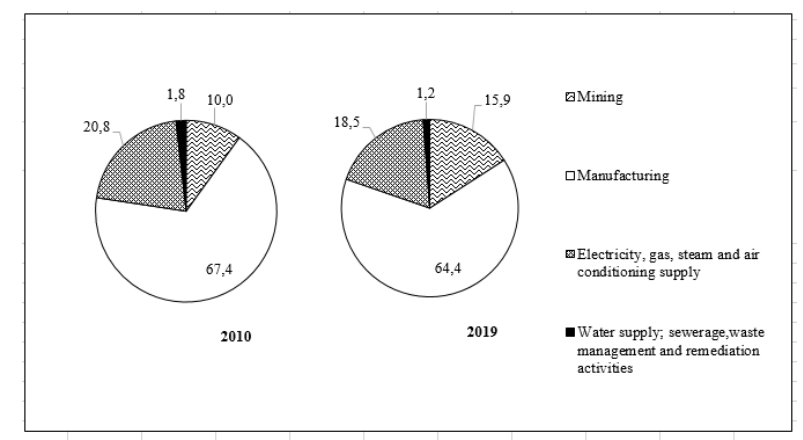

Fig. 2. The structure of industry by type of economic activity in 2010 and 2019 [9].

In turn, the processing industry is mainly ( $64.4 \%$ in 2019) formed by: production of food, beverages and tobacco products $(33.7 \%$ of the total processing industry in 2019); metallurgical production and production of finished metal products (25.3\%); production of chemicals and chemical products (14.1\%) and mechanical engineering (10.3\%). To date, the processing industry is dominated by production with a low level of technological processing: metallurgical production $(15.6 \%)$, production of wood and its products $(5.2 \%)$, production of coke and petroleum products $(6.3 \%), 6.3$ products $(4.0 \%)$. Moreover, we should pay attention to the long 
declining trend of the share of mechanical engineering production: from $13.8 \%$ in 2010 to $10.3 \%$ in 2019 .

During this period, the development of industrial production had the following features: the instability of the rate of recovery of growth after the crisis; intersectional uneven growth; annual fluctuations in certain types of production (eg food production, NACE section 10); different development trends within one type of activity (for example, beverage production: a decline in 2012-2019 half in the distillation, rectification and blending of alcoholic beverages, class 11.01 and a small increase of $1.9 \%$ in the production of grape wines, class 11.02).

Accordingly, in terms of the main types of industrial activity, the following changes took place:

- in the pharmaceutical market in 2019 there was an increase of $17.5 \%$ compared to 2012 in conditions of devaluation of the hryvnia, an increase in the cost of imported raw materials and a decline in the purchasing power of the population. Despite the inability of domestic companies to compete with global manufacturers of original drugs and the production of mostly generic drugs, leading Ukrainian firms are increasing their combined market share. In general, the annual growth of the drug market in physical terms over the past two years was $14 \%$, and growth was supported by the reform of public procurement in medicine, the introduction of reimbursement, external demand, which contributed to obtaining GMP certificates;

- in the market of woodworking products unsustainable growth in 2016-2017, but to reach the level of production in 2012 failed (94.6\%). Among the subtypes of activity there is an imbalance: sawmilling and planning production is growing faster - by an average of $4.3 \%$ annually, and production with significant processing - the manufacture of wood products, cork and others. $-1.7 \%$ per year. This market is one of the most promising, but for domestic production is determined by external demand, which formed a significant export-oriented production (86.4\% in 2019). At the same time, the development of this market is characterized by significant import dependence of production in the supply of raw materials (pulp, waste paper) and components;

- in the furniture market (NACE section 31), where after losing almost $20 \%$ of sales in 2014-2015, manufacturers reoriented to new markets, and due to the growth of domestic demand exceeded the level of production in 2019 compared to 2012 by $11.2 \%$. This was also facilitated by the progressive volume of Internet sales and cooperation of Ukrainian manufacturers with foreign ones.

Impact of Industry 4.0 technologies on transformations in important industries:

1. Since that fact that Industry 4.0 can provide customized solutions for consumer needs, even industries such as aerospace can experience the impact of advanced digital technology in manufacturing. Although the level of automation in the aerospace industry is already high enough, it will be even higher thanks to smart robotics in assembly. Some of this growth will be driven by more strict quality requirements, for example, for control that the parts have the minimum weight with the necessary strength and safety;

2. The technology of automatic control of transport will affect the reduction of logistics costs in the automotive industry;

3. The Industry 4.0 technologies implementation in the food industry begins with the identification of sources of raw materials and ends in the point of sale to the final consumer. The concept creates an "umbrella" management system that connects every step in the value chain, from food collection to final product consumption. At the same time blockchain technologies and the Internet of Things play an important role for the lowest possible costs and maximum possible output.

4. Industry 4.0 is expressed in the chemical industry mainly in two dimensions: improving the productivity of chemical production by various intelligent manufacturing technologies: predictive asset management, process control, and production modeling, including.

As well as reducing risk, it involves managing supply chains and internal operations to respond to changing customer needs and improve safety and quality.

According to the results of recent years, the industry has seen an increase in those types of industrial activities that were supported by investment, external and domestic consumer demand, as well as provided with agriculture and mining raw materials for processing (Fig. 3).

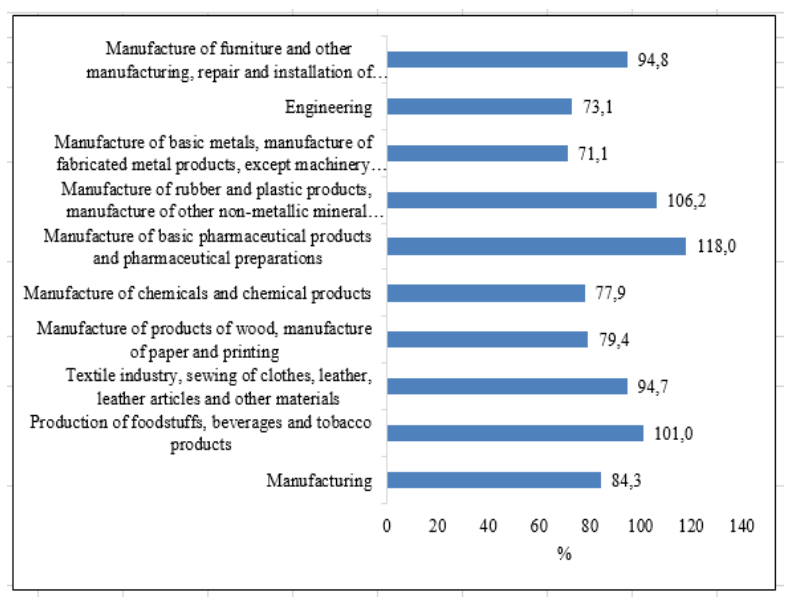

Fig. 3. Growth rates of production of processing industry 2012-2019, 2012=100\% [9].

Ukrainian industry has structural problems of foreign economic relations, which have reached a critical level, in particular the predominance of exports of intermediate goods $(44.7 \%$ in 2019). Share of exports of industrial goods to total exports of goods has reduced from $90.2 \%$ to $71.7 \%$ (at nearly 20 per cent). In addition, there are threatening growth trends in Ukrainian raw material exports - more than $70 \%$ of total industrial exports (low value - added products, including 30.7\% - metallurgical products; $12 \%$ - wood, pulp and paper products, etc.) and the growth of 
imports of high-tech products (almost a third increased imports of engineering products), which indicates the lag of the technological level of production from world indicators. Today, the industry operates in difficult economic conditions caused by systemic problems of the industry: significant depreciation of fixed capital, lack of financial resources for its renewal, dependence on imported raw materials. Compared to 2010, in 2019 the number of enterprises engaged in innovative activities in industry decreased to $15.2 \%$.

The most innovative manufacturing industries include (2019): production of basic pharmaceutical products and pharmaceuticals $(53.8 \%$ of the total number of industrial enterprises), production of computers, electronic and optical products (34\%), production of motor vehicles, trailers and semi-trailers and other vehicles (30.2\%), manufacture of electrical equipment $(25.2 \%)$, manufacture of chemicals and chemical products $(25 \%)$, manufacture of machinery and equipment $(22.6 \%)$, metallurgical production $(18.9 \%)$. However, in the volume of sold products of the processing industry only $1.2 \%$ is innovative. Moreover, the share of costs for innovative activities of machine-building industries to the volume of sold products is insignificant $-1.9 \%$ [10].

\subsection{The preliminary findings of the study}

In the process of spreading the technologies of Industry 4.0 , the place of the processing industry in the structure of the economy remains significant with a radical change in its qualitative characteristics. Today, the share of traditional industries in the industrial structure of the EU countries is at least $88 \%$. However, the development of high-tech industries is decisive for both the national economy as a whole and for individual, predominantly industrial regions. It seems that in the context of the fourth industrial revolution, one should focus on innovative economic growth, manifested in an increase in the growth rate of macroeconomic indicators along with an improvement in the distribution of the results of such growth, in the expansion of equality of opportunities for all members of society.

Of particular importance among the technologies of Industry 4.0 is blockchain, which can be considered as an effective tool for solving the problems of industrial enterprises in big data management and analysis using artificial intelligence. This technology has three important properties: decentralization, immutability and integrity. During the COVID-19 pandemic, tracking and monitoring goods and services has become a new priority for many companies in supply chain management. And that's the kind of thing that blockchain technology does. They can be useful for companies in a variety of industries from heavy industry to fashion. These technologies enable to solve the requirement of social and environmental responsibility issues from the public and investors and help to substantiate the selection of suppliers.
Blockchain is an important cross-cutting technology in the digital economy by which developing countries can beneficially integrate into the world economy.

Expectations are especially high for blockchain in combination with other technologies, such as the Internet of Things. Blockchain is a basis for easier interaction between devices, which are autonomously administers. This facilitates various types of transactions between devices, such as registering a new device, authenticating remote users, and contacting to exchange with other devices. Blockchain would lead eventually to reduce transaction costs, supply chains and increased business competitiveness.

Intensive processes of structural transformation of the economy are taking place in the world, which are accompanied by an increase in uneven development and general uncertainty. For a number of countries seeking to cope with acute internal problems, overcome the existing serious imbalances in the structure of the economy or respond to external challenges, it is important to formulate a policy of structural transformation. In these conditions, there is an active search for new solutions for structural policy, understood as industrial policy in a broad sense (industrial policy), that is, government actions aimed at improving the business environment or the structure of economic activity in sectors or technological areas that will provide better prospects for economic growth and the creation of public goods versus no government intervention.

Considering the experience of the developed countries of the world in implementing structural transformations, we can note that most of the leading countries, through their structural policies, seek to create conditions for industrial growth and the competitiveness of the economy. For example, developing countries are trying to overcome the middle-income trap, as well as to carry out a technological "upgrade" of the economy, the Gulf countries use it to diversify their national economies, and a number of African countries see it as a means of overcoming poverty. The EU industrial policy is specifically aimed at accelerating the adaptation of industry to structural changes; creating an environment favorable for the initiative and development of enterprises in the EU, especially small and mediumsized ones; creating an environment conducive to cooperation between enterprises; promoting better use of the industrial potential of innovation, research and technological development policies. Following the best practices of developed countries, Ukraine should form an active industrial policy to ensure the prospects for economic growth and overcome the accumulated structural problems and imbalances in the development of industry caused by the incompleteness and inconsistency of reforms, deepened by world crises, political and military confrontation with the Russian Federation. The negative impact of external factors was partially mitigated after the signing of the Association Agreement with the EU by gradual adaptation of national legislation in accordance with international 
best practices, improvement of the business climate and deregulation of business activities, development of public-private partnerships.

Implementation of circular economy principles is particularly important for structural transformation of economy.

The introduction of the principles of a circular economy into manufacturing makes it possible to overload the economy, making it more stable and competitive. It would be beneficial for all enterprises, industries and citizens in such areas as more innovative and efficient ways of production and consumption; securing sufficient resources for business and volatile prices; opportunities for localization and social integration; optimization of waste management, promotes waste recycling and reducing the volume of landfills; energy savings as there are fewer production processes require less energy; benefits for the environment in terms of climate and biodiversity, reducing air, soil and water pollution.

The greatest benefit would result from replacing old equipment with modern, which saves energy. In addition, emphasis should be placed on the development of renewable energy sources - in the near future it would be only environmentally friendly, but also cost less than energy from traditional sources. There are also strong multiplier effect might be a circular economy development. The basis of a circular economy is implementation of circular supply chain, that maximize the added value throughout the product life cycle.

The foregoing calls for the formulation of a development and implementation the effective tools for supporting industry to increase its efficiency while reducing environmental load, namely the following directions of state incentives: improvement of legal regulation, implementation of principles sustainable development, financial support for developmentoriented projects circular economy, as well as the development of regional waste management plans with focusing on the European Green Deal.

\section{Conclusion}

Given the significance of the development of high-tech industries for the competitiveness of the national economy, it is important to ensure the mechanisms of production, that are not contrary to the rules of international law. Among organizational and economic activities, which have directly or indirectly affect through the technological introduction on the markets of industrial goods and services, are the regulator and management, inspection, information support.

Annually, one of them is the establishment of a manufacturing economy as a whole, and its industrial production, as well as its digital development: technological, production and economic basis and a set of management tools. As a result of digitalization of industrial development, it is supervised by new innovations, improved productivity of practice, optimization of the structure of costs, and expanded fenestration technologies [10].

Industry 4.0 provides for the promotion of digital technologies at enterprises, attracting relevant specialists, increasing the availability of special software tools, introducing and developing information systems, databases, computing power, and spreading cloud services technology. As a result, the expected changes in the industry may be characterized by an increase in labor productivity, efficiency of production and sales of metal products, a decrease in transaction costs, an increase in innovation activity and an improvement in the quality of industrial products with a high share of added value.

It is argued that technological transformations of Industry 4.0 provide new opportunities to remote control features that allows to place production facilities in any place where there is Internet connection. Industry 4.0 technologies have been found to have a significant impact on the global transformation of the worldnamely, production organization as a set of networks linked to global value chains. Today, virtually all value-added activities, including development, design, manufacturing, testing, marketing and implementation, can be digitized. In addition, the development of the Internet of Things allows for interaction between machines and people with a high level of precision and efficiency.

Digital technologies are the driving force of structural transformation in industry due to changes in production and logistics models. Considering the above, we can highlight new technological trends for the industrial development of Ukraine, that :

- the growth of consumer requirements for the quality of products in terms of a set of properties, are mostly individual in nature;

- a new level of automation of industrial production systems;

- growing flexibility of strategic decisions in the selection of promising technologies and their resource provision, taking into account the complex of the latest materials;

- development and expansion of the functionality of SMART technologies of modern production based on the latest materials;

- anchoring digital technologies in the product value chain.

Consequently, global trends and analysis help us to propose such solutions for enhancing Industry 4.0 in Ukrainian industry:

- development of network structures; development of mini and SMART factories;

- transition to new business models corresponding to the conditions for the development of Industry 4.0;

- the formation of new development institutions that promote artificial intelligence, additive technologies, the Internet of things, BIG DATA, production robotization; supplementing basic instruments with venture financing instruments; 
-development of public, educational and scientific institutions that provide an increase in the qualification level of personnel, the expansion of project innovation. The benefits derived from Industry 4.0 in industrial sector will have a multiplier effect on the whole economy.

\section{References}

1. V.M. Heyets, The fenomenon of instability as a challenge to economic development, (NAS of Ukraine, 2020)

2. Yu. I. Pilipenko, I. Yu. Guzenko, Econ. Sp., 129, 89 (2018)

3. Yu. Kindzersky, Ukr Econ. 11. 48. (2017).

4. J. P. Martino, Techn. For. and Soc. Ch., 70, 719. (2003)

5. R. Kurzweil, Kurzweil Library. (2021). URL: https://www.kurzweilai.net/the-law-ofaccelerating-returns

6. Handbook on constructing composite indicators: methodology and user guide. OECD. (2008). URL: http://www.oecd.org/sdd/42495745.pdf

7. United Nations conference on trade and development. Structural transformation for inclusive and sustainable growth. Trade and development report. (2016). URL: https://unctad.org/en/PublicationsLibrary/tdr2016 ru.pdf

8. State Statistics Service of Ukraine. (2021). URL: https://prm.ua/derzhstat-oprilyudniv-dani-pro-vvpukrayini-pislya-karantinu-ekonomika-prosila-na11-4

9. Database of State Statistics Service of Ukraine. (2021). URL:

http://www.ukrstat.gov.ua/operativ/menu/ menu_u/prom.htm

10. L.V. Deineko, N.G. Gakhovich, O.M.

Kushnirenko, Industrial policy as a key tool of development strategy (NAS of Ukraine, 2019) 